\title{
CYP4F13 is the Major Enzyme for Conversion of alpha-Eleostearic Acid into cis-9, trans-11-Conjugated Linoleic Acid in Mouse Hepatic Microsomes
}

\author{
Qiming Wu and Tsuyoshi Tsuduki* \\ Laboratory of Food and Biomolecular Science, Graduate School of Agriculture, Tohoku University, Sendai 980-8572, JAPAN
}

\begin{abstract}
Our previous studies have shown that $\alpha$-eleostearic acid ( $\alpha$-ESA; cis-9, trans-11, trans-13 (c9,t11,t13)-conjugated linolenic acid (CLnA)) is converted into c9,t11-conjugated linoleic acid (CLA) in rats. Furthermore, we have demonstrated that the conversion of $\alpha$-ESA into CLA is a nicotinamide adenine dinucleotide phosphate (NADPH)-dependent enzymatic reaction, which occurs mostly in the rat liver. However, the precise metabolic pathway and enzyme involved have not been identified yet. Therefore, in this study we aimed to determine the role of cytochrome P450 (CYP) in the conversion of $\alpha$-ESA into c9,t11CLA using an in vitro reconstitution system containing mouse hepatic microsomes, NADPH, and $\alpha$-ESA. The CYP4 inhibitors, 17-ODYA and HET0016, performed the highest level of inhibition of CLA formation. Furthermore, the redox partner cytochrome P450 reductase (CPR) inhibitor, 2-chloroethyl ethyl sulfide (CEES), also demonstrated a high level of inhibition. Thus, these results indicate that the NADPHdependent CPR/CYP4 system is responsible for CLA formation. In a correlation analysis between the specific activity of CLA formation and $C y p 4$ family gene expression in tissues, Cyp4a14 and Cyp4f13 demonstrated the best correlations. However, the CYP4F substrate prostaglandin $\mathbf{A}_{1}\left(\mathbf{P G A}_{1}\right)$ exhibited the strongest inhibitory effect on CLA formation, while the CYP4A and CYP4B1 substrate lauric acid had no inhibitory effect. Therefore, we conclude that the CYP4F13 enzyme is the major enzyme involved in CLA formation. This pathway is a novel pathway for endogenous CLA synthesis, and this study provides insight into the potential application of CLnA in functional foods.
\end{abstract}

Key words: cytochrome P450, conjugated linolenic acid, conjugated linoleic acid, alpha-eleostearic acid, conversion

\section{Introduction}

Conjugated linoleic acid (CLA; C18:2) is a collective term for geometric and positional isomers of linoleic acid (cis9,cis12-18:2) with two conjugated double bonds. There are 56 different isoforms of CLA as a result of the various arrangement of double bonds, including positional $(6,8 ; 7,9$; 8,$10 ; 9,11 ; 10,12 ; 11,13 ; 12,14$; and 13,15), and geometric (cis/cis; cis/trans; trans/trans; or trans/cis) variations ${ }^{1)}$. Several of them, and in particular, cis-9,trans-11 (c9,t11)and $t 10, c 12$-CLA were reported to have various beneficial effects on physiological functions, such as anti-obesity and anticarcinogenic activities, immune enhancement, bone formation improvement, and lipid metabolism regulation in in vivo and in vitro studies, ${ }^{1,2}$. Based on these benefits, CLA-rich foods are considered as functional foods. CLA is commonly found in dairy products and ruminant meat, which are the main sources of CLA for humans. However,
CLA is naturally present in very small amounts in these foodstuffs which typically contain fat in the range from 2.9 to $8.9 \mathrm{mg} / \mathrm{g}^{3)}$. As the CLA intake from dietary sources is far from the intended effective dosage due to the low content of CLA in nature ${ }^{4)}$, it is necessary to supplement the human diet with CLA. Generally, the CLA in supplements is not derived from natural foods but prepared by chemically altering the linoleic acid found in vegetable oils. It is important to note, however, that the balance of the different CLA isoforms is heavily distorted in supplements because they contain types of CLA isoforms that are never found in large amounts in nature. The c9,t11-CLA is believed to be the most common natural form of CLA comprising 80 to $90 \%$ of the total CLA in food products from ruminants, whereas t10,c12-CLA is present at a level of $3-5 \%$, and other isomers are present in very small amounts $^{5,6}$. Most of the commercially available CLA sup-

\footnotetext{
*Correspondence to: Tsuyoshi Tsuduki, Laboratory of Food and Biomolecular Science, Graduate School of Agriculture, Tohoku University, Sendai 980-8572, JAPAN

E-mail: tsudukit@tohoku.ac.jp

Accepted April 22, 2020 (received for review March 26, 2020)

Journal of Oleo Science ISSN 1345-8957 print / ISSN 1347-3352 online

http://www.jstage.jst.go.jp/browse/jos/ http://mc.manusriptcentral.com/jjocs
} 
plements contain almost equal amounts of the two major isomers c9,t11-CLA (40.85-41.1\%) and t10,c12-CLA (43.5$44.9 \%$ ), and levels of other CLA isomers $(4.6 \%-10 \%)^{7}$. However, it has been reported that mice fed the highly purified t10,c12-CLA isomer had adverse side effects such as insulin resistance, robust hyperinsulinemia, and massive liver steatosis ${ }^{8-10)}$. Furthermore, insulin resistance has also been detected in obese men treated with purified t10,c12$\mathrm{CLA}^{11)}$, which raises concerns about the safety of dietary supplements containing the t10,c12-CLA isomer. On the other hand, c9,t11-CLA, which was found to improve the increased insulin resistance caused by t10,c12-CLA ${ }^{9,12)}$, is considered safer due to fewer reported side effects. For these reasons, CLA supplements do not provide the same health effects as CLA from natural foods.

In contrast to the generally low content of CLA in nature, the content of conjugated linolenic acid (CLnA; C18:3) with three conjugated double bonds in seed oil from certain plants can comprise up to $\sim 80 \%$ of the total lipid content. For example, $\alpha$-eleostearic acid ( $\alpha$-ESA; c9,t11,t13-CLnA) comprises up to $60 \%$ (wt/wt) of the total lipid content of bitter gourd seed oil and $76 \%$ of the total lipid content of tung seed oil, whereas punicic acid (PA; c9,t10,c13-CLnA) comprises up to $74.5 \%$ of the total lipid content of pomegranate seed oil, and jacaric acid (JA; c8,t10,c12-CLnA) is found at a concentration of $15.9 \%$ in jacaranda seed oil. We are particularly interested in these CLnA-rich seed oils, because CLnA is the only conjugated fatty acid that can be prepared from natural sources in bulk ${ }^{13)}$. Our previous studies have also shown that CLnA has a stronger anti-tumor effect than CLA in vitro and in vivo. Moreover, $\alpha$-ESA has been reported to have a strong antiangiogenic effect, a new confirmed physiological effect of $\alpha-\mathrm{ESA}^{14-17)}$. We first reported that $\alpha$-ESA was converted into c 9 ,t11CLA in $1 \% \alpha$-ESA-fed rats. The structure of c9,t11-CLA was determined using gas chromatography-electron impact/mass spectrometry (GC-EI-MS) and ${ }^{13} \mathrm{C}-\mathrm{NMR}$. Furthermore, we have demonstrated that this conversion is a $\Delta 13$ saturation, an NADPH-dependent enzymatic reaction occurring mostly in the rat liver ${ }^{18,19)}$. Moreover, we observed similar conversions of CLnA into CLA in PA- and JA-fed rats, where PA was converted into c9,t11-CLA and JA was converted into c8,t10-CLA ${ }^{13,20)}$. These conversions were also confirmed in mice and humans in other reports ${ }^{21-23)}$.

In ruminants, CLA is formed as an intermediate during the ruminal bio-hydrogenation of linoleic acid to stearic acid (18:0) by B. fibrisolvens and other rumen bacteria ${ }^{24)}$. Another pathway involves $\Delta 9$-desaturase-dependent endogenous CLA synthesis from vaccinia acid (t11-18:1), another intermediate in ruminal biohydrogenation ${ }^{5,25)}$. Although the major source of CLA in humans comes from dietary intake, endogenous synthesis of CLA has also been reported in humans and other non-ruminants ${ }^{26-28)}$. Accordingly, the conversion of CLnA into CLA could be a novel pathway for endogenous CLA synthesis. As CLnA can be prepared more easily than CLA, once the mechanism of this conversion is elucidated, it is expected that CLnA, especially $\alpha$-ESA will be a new source for CLA synthesis or supplant CLA as a dietary supplement.

Our previous studies indicated that the NADPH-dependent enzyme involved in this conversion should be classified as part of the drug metabolism, but not as part of the $\beta$-oxidation enzyme group in the fatty acid metabolic pathway $^{18)}$. However, the precise metabolic pathway and enzyme involved have not been identified yet. The superfamily of cytochrome P450 (CYP) enzymes is considered the major enzyme family responsible for the phase I metabolism (reduction, oxidation, or hydrolysis reactions) of numerous endogenous and exogenous compounds, such as drugs and other xenobiotics ${ }^{29)}$. The in vivo reactions catalyzed by CYP enzymes require the cofactor NADPH as the electron source and the redox partner of cytochrome P450 reductase (CPR), which functions in the electron transfer from NADPH to CYP in microsomes ${ }^{30)}$. Based on these considerations, we sought to elucidate whether CYPs play a role in the conversion of $\alpha$-ESA into CLA. For this purpose, we aimed to determine the subcellular distribution of enzymatic activity in mouse liver by using an in vitro reconstitution system of enzymatic activity containing mouse hepatic microsomes, NADPH, and $\alpha$-ESA to test the effect of various inhibitors and CYP-substrates on c9,t11-CLA formation. Moreover, we aimed to determine the enzymatic activities and Cyp 4 family gene expression levels in various tissues for correlational analysis.

\section{Experimental Procedures \\ 2.1 Materials}

Tung oil and standard CLA oil were obtained from the Nisshin OilliO Group, Ltd. NADPH, NADP ${ }^{+}, \mathrm{NADH}$, and $\mathrm{NAD}^{+}$were purchased from Oriental Yeast Co., Ltd. (Tokyo, Japan). Trimethylsilyldiazomethane $\left(\mathrm{TMSN}_{2} \mathrm{CH}_{3}\right)$, trimethylolaminomethane acetate (Tris-actate), fluvoxamine, ticlopidine, montelukast, fluconazole, chlormethiazole, and ketoconazole were purchased from Tokyo Chemical Industry(Tokyo, Japan). Indomethacin, niflumic acid, 2-chloroethyl ethyl sulfide (CEES), 17-octadecynoic acid (17-ODYA), and HET0016 were purchased from Sigma-Aldrich (St. Louis, MO). Lauric acid, palmitic acid, stearic acid, oleic acid, linoleic acid, linolenic acid, arachidonic acid, prostaglandin A1, sulfaphenazole, and quinidine were obtained from Cayman Chemical Company (Ann Arbor, MI). All other chemicals (sucrose, EDTA $22 \mathrm{Na} \cdot 2 \mathrm{H}_{2} \mathrm{O}$, DTT, PMSF) were purchased from Wako Pure Chemical Industries, Ltd. 


\subsection{Methods}

\subsubsection{Animals}

All animal experiments were conducted in accordance with the Regulations for Animal Experiments and Related Activities at Tohoku University (2018AgA-015) ${ }^{31}$. Institute of Cancer Research (ICR) mice, 13 weeks old, were obtained from CLEA Japan Inc. and were allowed to acclimate to the facility for 1 week with standard chow diet (CE-2, CLEA Japan) before the initiation of the experiments. At 14 weeks of age, the mice were sacrificed by decapitation after an overnight fast for $12 \mathrm{~h}$ and the following tissues were collected: liver, kidney, small intestine, pancreas, brain, heart, lung, spleen, epididymal white adipose tissue (eWAT), and brown adipose tissue (BAT). All tissues were stored at $-80^{\circ} \mathrm{C}$ until use.

2.2.2 Enzymatic activity assay

To prepare the enzyme substrate $\alpha$-ESA (free fatty acid form), tung oil was hydrolyzed by potassium hydroxide $(\mathrm{KOH})$ as previously reported with a slight modification ${ }^{17)}$. After bubbling with nitrogen gas for $15 \mathrm{~s}, 30 \mathrm{mg}$ of tung oil in a glass test tube was saponified with $0.25 \mathrm{~mL}$ of $0.3 \mathrm{M}$ $\mathrm{KOH}$ in $2.5 \mathrm{~mL}$ methanol at $40^{\circ} \mathrm{C}$ for $90 \mathrm{~min}$. After cooling to room temperature, $2.5 \mathrm{~mL}$ of $\mathrm{H}_{2} \mathrm{O}$ and $5 \mathrm{~mL}$ of hexane were added. The reaction mixture was vigorously vortexed for 2 min and centrifuged at $500 \times g$ for 5 min to separate the organic layer from the aqueous layer. The top organic layer containing non-saponaceous material was removed, while the bottom aqueous layer was mixed with $1.5 \mathrm{~mL}$ of $6 \mathrm{M} \mathrm{HCl}$ and $5 \mathrm{~mL}$ of hexane to extract the fatty acids. The mixture was vigorously vortexed for $2 \mathrm{~min}$ and centrifuged at $500 \times g$ for $5 \mathrm{~min}$. The top organic layer was then concentrated by solvent evaporation under vacuum, dissolved in dimethyl sulfoxide(DMSO), and stored at $-80^{\circ} \mathrm{C}$ until use.

For detecting enzymatic activity, each one of the frozen biological samples (a total of 10 tissue samples) was homogenized in 9 volumes (w/v) of chilled $0.01 \mathrm{M}$ Tris-acetate sucrose buffer, pH 7.4, containing 0.01 M Tris-Acetate, 0.25 M Sucrose, $1 \mathrm{mM}$ dithiothreitol(DTT), $1 \mathrm{mM}$ phenylmethylsulfonyl fluoride (PMSF), $1 \mathrm{mM}$ ethylenediaminetetraacetic acid (EDTA) ${ }^{18)}$, by using the bead-type homogenizer Micro Smash MS-100 (TOMY Seiko, Tokyo, Japan) at 3600 rpm for $30 \mathrm{sec} \times 3$ times. To unify the enzymatic reaction time, the experiments were performed in a crushed-ice bath. A total of $450 \mu \mathrm{L}$ of homogenate $(10 \% \mathrm{w} / \mathrm{v})$ was mixed with $10 \mu \mathrm{L}$ of $\alpha$-ESA substrate ( $5 \mathrm{mM}$ in DMSO) and $40 \mu \mathrm{L}$ of coenzyme NADPH $(0.1 \mathrm{M}$ in $0.9 \% \mathrm{NaCl})$, followed by incubation at $37^{\circ} \mathrm{C}$ for $30 \mathrm{~min}$. The reaction was stopped by placing the sample in a crushed-ice bath and a known amount of the internal standard heptadecanoic acid (C17:0) was added in order to quantify the fatty acids. The lipids in the reaction mixture were extracted with chloroform-methanol-water (1:1:0.9 in volume) according the Blight \& Dyer method. The free fatty acids in the lipid extract were then catalyzed into methyl ester derivatives by the $\mathrm{TMSN}_{2} \mathrm{CH}_{3}$ method ${ }^{32}$ for gas chromatography (GC) analysis to determine the CLA concentration. The protein concentration was determined by the Pierce BCA protein assay kit (Thermo Scientific, Houston, TX, USA). The specific activity of the conversion of $\alpha$-ESA into CLA was obtained after normalizing to the total protein using the following formula: specific activity $(\mathrm{nmol} / \mathrm{min} / \mathrm{g}$ protein $)=$ CLA amounts (nmol)/ time taken (min)/ protein (g) .

2.2.3 Gas chromatography analysis of fatty acids

The fatty acid methyl esters (FAMEs) were analyzed by GC (GC-4000 Plus, GL Science Inc., Tokyo, Japan) equipped with a Supelcowax-10 fused silica capillary column $(60 \mathrm{~m} \times$ $0.32 \mathrm{~mm} \times 0.25 \mu \mathrm{m}$ film thickness, Supelco, Bellefonte, PA) and a flame ionization detector ${ }^{20)}$. Helium was used as a carrier gas at a constant pressure of $400 \mathrm{kPa}$. The temperatures of the injector and detector were $200^{\circ} \mathrm{C}$ and $250^{\circ} \mathrm{C}^{13)}$, respectively, and the oven temperature program was as follows: an initial temperature of $50^{\circ} \mathrm{C}$ was ramped to $220^{\circ} \mathrm{C}$ at a rate of $20^{\circ} \mathrm{C} / \mathrm{min}$ and held for $30 \mathrm{~min}$, then ramped to $250^{\circ} \mathrm{C}$ at a rate of $20^{\circ} \mathrm{C} / \mathrm{min}$ and held for $20 \mathrm{~min}$. Each peak was annotated by comparing the retention times with CLA FAMEs standards and GLC reference standards of FAMEs (Nu-Chek-Prep, Elysian, MN, USA).

2.2.4 Characterization of $\alpha$-ESA saturase

In order to further understand the characteristics of the conversion of $\alpha$-ESA into CLA, the liver homogenate, $\mathrm{NADPH}$, and $\alpha$-ESA in the reaction mixture, were gradually replaced by $0.01 \mathrm{M}$ Tris-acetate sucrose buffer, $0.9 \% \mathrm{NaCl}$ solution, and DMSO, respectively. After incubation at $37^{\circ} \mathrm{C}$ for $30 \mathrm{~min}$, the specific activity of $\alpha$-ESA conversion into CLA was measured, as explained above.

To further confirm whether other coenzymes could initiate the reaction, $40 \mu \mathrm{L}$ of $0.1 \mathrm{M}$ coenzyme $\left(\mathrm{NADPH}, \mathrm{NADP}^{+}\right.$, $\mathrm{NADH}$, and $\mathrm{NAD}^{+}$were all dissolved in $0.9 \% \mathrm{NaCl}$ solution) was added individually in the presence of the homogenate and $\alpha$-ESA. Subsequently, the reaction mixture was processed as described above to measure the specific activity of $\alpha$-ESA conversion into CLA. Experiments with heated liver homogenate (incubations conducted at $60^{\circ} \mathrm{C}$ for $30 \mathrm{~min}$ ) were also performed to further assess the role of the homogenate in the conversion of $\alpha$-ESA into CLA.

To elucidate the subcellular distribution of $\alpha$-ESA saturase, the liver homogenate was centrifuged at $600 \times \mathrm{g}$, at $4^{\circ} \mathrm{C}$ for $10 \mathrm{~min}$ to collect the pellet containing intact nuclei and debris. The nuclear pellet was re-suspended into 1 volume of $0.01 \mathrm{M}$ Tris-acetate sucrose buffer and the postnuclear supernatant was again centrifuged at $8000 \times \mathrm{g}$, at $4^{\circ} \mathrm{C}$ for 20 min using an Optima L-100 XP Ultracentrifuge with a type 70.1 Ti fixed-angle rotor(Beckman Coulter Ltd., Fullerton, CA) to sediment mitochondria. The mitochondrial pellet was re-suspended into 1 volume of the of $0.01 \mathrm{M}$ Tris-acetate sucrose buffer and the post-mitochondrial supernatant was further ultracentrifuged at $105000 \times$ 
$g$, at $4^{\circ} \mathrm{C}$ for 60 min to obtain microsomes ${ }^{33)}$. The microsomal pellet was also re-suspended into 1 volume of the same buffer and the cytosolic supernatant was retained. A total of $450 \mu \mathrm{L}$ of each subcellular fraction, namely nuclear, mitochondrial, microsomal, and cytosolic, was subjected to an enzymatic activity assay and the amounts of CLA were determined by GC analysis.

2.2.5 Inhibitory effect of inhibitors and CYP-substrates

To evaluate the inhibitory effect of inhibitors (CYP-selective inhibitors, COX inhibitors, and CPR inhibitor) in CLA formation, liver microsomes (10 mg protein $/ \mathrm{mL}$ ) were preincubated with inhibitors or DMSO solvent, which was used as the control, at $37^{\circ} \mathrm{C}$ for $5 \mathrm{~min}$. Then, the pre-incubated mixtures were immediately subjected to the CLA formation assay as explained above. The $\mathrm{IC}_{50}$ (concentration of inhibitor required to cause a $50 \%$ inhibition of the original enzyme activity) was determined graphically from the plot of the logarithm of inhibitor concentration versus the percentage of CLA remaining (\% of control)after inhibition using GraphPad Prism 7(GraphPad Software, San Diego, CA, USA). To determine the inhibitory effect of CYP-substrates on CLA formation, liver microsomes (10 mg protein/ $\mathrm{mL})$ were pre-mixed simultaneously with $\alpha$-ESA and CYPsubstrates $(\alpha$-ESA: CYP-substrates $=1: 1$ or $1: 4$ in mole ratio) before the addition of NADPH, which initiated the reaction. Following this, the mixtures were incubated at $37^{\circ} \mathrm{C}$ for $30 \mathrm{~min}$ as described above for the enzymatic activity assay and the amounts of CLA were determined by GC analysis.

2.2.6 Cyp 4 family messenger RNA expression analysis

For the purification of high-quality RNA, the RNeasy Mini Kit (Qiagen, Valencia, CA, USA) was used for liver, kidney, small intestine, pancreas and spleen samples, while the RNeasy Lipid Tissue Mini Kit (Qiagen, Valencia, CA, USA) was used for brain, eWAT, and BAT samples. The RNeasy Fibrous Tissue Mini Kit (Qiagen, Valencia, CA, USA) was used for total RNA isolation from cardiac tissue according to the protocol given by the manufacturer. The concentration and purity of the isolated RNA was determined using the Nanodrop 1000 spectrophotometer (Thermo Scientific, Wilmington, MA, USA). Subsequently, reverse transcription of RNA to complementary DNA (cDNA) was performed with the PrimeScript ${ }^{\circledR}$ RT Master Mix (Perfect Real Time) Kit (Takara Bio Inc., Shiga, Japan) ${ }^{34)}$. Briefly, an aliquot volume of $1000 \mathrm{ng}$ of RNA, $4 \mu \mathrm{L}$ of $5 \times$ PrimeScript RT Master Mix (Perfect Real Time) and RNasefree distilled water up to $20 \mu \mathrm{L}$ were mixed and incubated at $37^{\circ} \mathrm{C}$ for $10 \mathrm{~min}$, and then at $85^{\circ} \mathrm{C}$ for $5 \mathrm{sec}$. Finally, 480 $\mu \mathrm{L}$ of RNase-free $\mathrm{dH}_{2} \mathrm{O}$ was added to dilute the cDNA and the samples were stored at $-20^{\circ} \mathrm{C}$ for subsequent analysis.

The cDNA was used for real-time quantitative reverse transcriptase polymerase chain reaction (qRT-PCR) to analyze the expression levels of Cyp 4 family genes. The qRT-PCR reaction was prepared in a final volume of $20 \mu \mathrm{L}$ containing $10 \mu \mathrm{L} 2 \times \mathrm{TB}_{\text {Green }}{ }^{\circledR}$ Premix Ex Taq ${ }^{\mathrm{TM}}$ (Tli RNaseH Plus) (Takara Bio Inc., Shiga, Japan), $1 \mu \mathrm{L}$ forward $\operatorname{primer}(10 \mu \mathrm{M}), 1 \mu \mathrm{L}$ reverse primer $(10 \mu \mathrm{M})$ and $10 \mu \mathrm{L}$ diluted cDNA. The gene-specific primers, purchased from Sigma-Aldrich (Merck KGaA), are shown in Table 1. PCR amplification was performed with a CFX Connect ${ }^{\mathrm{TM}}$ RealTime PCR Detection System (Bio-Rad, California, USA) and each biological sample was assayed in two technical replicates. The reactions were subjected to an initial 30 sec denaturation at $95^{\circ} \mathrm{C}$. To verify the specificity of the amplification reaction, a melting curve analysis was performed in the range of $60^{\circ} \mathrm{C}$ to $95^{\circ} \mathrm{C}, 0.5^{\circ} \mathrm{C}$ per $5 \mathrm{sec}$ increments after thermo-cycling for each reaction ${ }^{35)}$. The threshold cycle (Ct) value, representing the PCR cycle at which an increase in reporter fluorescence signal significantly above the background fluorescence can first be detected, was also determined. The expression levels of the Cyp 4 family genes (10 genes total) in each biological sample was normalized to tissue weight, and shown as fold changes relative to the corresponding Cyp 4 transcripts in the liver.

Table 1 List of primer sequences used for real-time PCR.

\begin{tabular}{llll}
\hline \multicolumn{1}{c}{ Gene name } & \multicolumn{1}{c}{ Accession Number } & \multicolumn{1}{c}{ Forward Primer $\left(5^{\prime}-3^{\prime}\right)$} & \multicolumn{1}{c}{ Reverse Primer (5’ -3’ $)$} \\
\hline Cyp4a10 & NM_010011 & GCTACTCAAGGCTTTCCAGCAG & CCAGAACCATCTAGGAAAGGCAC \\
Cyp4a12a/b & NM_017396/NM_172306 & CTCATTCCTGCCCTTCTCAG & GGTATGGGGATTGGGACTCT \\
Cyp4a14 & NM_007822 & CAAGACCCTCCAGCATTTCC & GAGCTCCTTGTCCTTCAGATGGT \\
Cyp4b1 & NM_007823 & CACCTGGACTTCCTCGACAT & TCATCCCACTGGAAGGAGTC \\
Cyp4f13 & NM_130882 & CATCTTGGATTCTAGCCCGAA & GAAGCAACGAAGGCGACTG \\
Cyp4f14 & NM_022434 & ACTGGCTTATGGGTCACGTG & ACCCACCAAACGAGTCAATTC \\
Cyp4f15 & NM_134127 & CATGACATGGCTGGGTCCTA & GAGGCATTGAGAACAGATCGA \\
Cyp4f16 & NM_024442 & CCTTGCCTGGACTTACTCATT & GTAACCAGCTGCATGCCTTC \\
Cyp4f17 & NM_001101445 & AAAACATTTCCAGGGAAGAGC & GGAGACGGCAGTAGTTGTCATA \\
Cyp4f18 & NM_024444 & AGAGCCTGGTGCGAACCTT & TGGAATATGCGGATGACTGG \\
\hline
\end{tabular}




\subsection{Statistical analysis}

Data are presented as mean \pm standard deviation (SD) and were analyzed with one-way analysis of variance (ANOVA), followed by Tukey-Kramer test for comparisons among more than two groups. A $P$ value of $<0.05$ was considered statistically significant. For correlation studies, the specific activity of CLA formation was normalized to the corresponding tissue weight. The correlations between the tissue specific activity and the relative expression level of Cyp 4 family genes were described using Spearman's rank correlation coefficients $\left(r_{s}\right)$. The strength of correlation was ranked as follows: for absolute values of $r_{s}, 0.01-0.19$ was regarded as negligible, $0.20-0.29$ as weak, $0.30-0.39$ as moderate, $0.40-0.69$ as strong, and $\geq 0.70$ as very strong ${ }^{36)}$.

\section{Results}

\subsection{Characterization of $\alpha$-ESA saturase in vitro}

To characterize the conversion of $\alpha$-ESA into CLA, liver homogenate, $\alpha$-ESA, and NADPH in the in vitro reconstitution system were replaced by their corresponding solvents. However, CLA formation was not detected in the absence of any one of the ingredients (Fig. S1). Only the liver homogenate could convert $\alpha$-ESA into CLA in the presence of $\mathrm{NADPH}$, indicating that the converting process was an enzyme-mediated metabolic process. To further confirm whether other coenzymes could initiate the reaction, either NADP, NADH, or NAD was added to the in vitro reconstitution system instead of NADPH. However, in the presence of NADP, NADH, or NAD the CLA level was below the detectable limit due to a high preference for $\mathrm{NADPH}$ (Fig. S2). Furthermore, the heated liver homogenate incubated with $\alpha$-ESA and NADPH also showed no activity (Fig. S2), demonstrating that the metabolism of $\alpha$-ESA into CLA occurs through an NADPH-dependent enzymatic reaction. In the $\alpha$-ESA saturase subcellular localization experiment in the liver homogenate, the enzymatic activity was the highest in the microsomal fraction, followed by the mitochondrial fraction, lower in the nuclear fraction, and absent in the cytosolic fraction(Fig. 1). Therefore, it was confirmed that $\alpha$-ESA saturase required $\mathrm{NADPH}$ as the source of electrons and was abundant in microsomes, which contain the major CYP drug-metabolizing enzymes. For these reasons hepatic microsomes were used in the next experiments.

\subsection{The effect of inhibitors on CLA formation}

To explore whether the CYP enzymes were involved in CLA formation, the various CYP-specific inhibitors were selected to validate their inhibitory effect on CLA formation in hepatic microsomes. With the exception of fluconazole (CYP2C19 inhibitor) and ketoconazole (CYP3A4 inhibitor), all the other CYP-specific inhibitors, namely
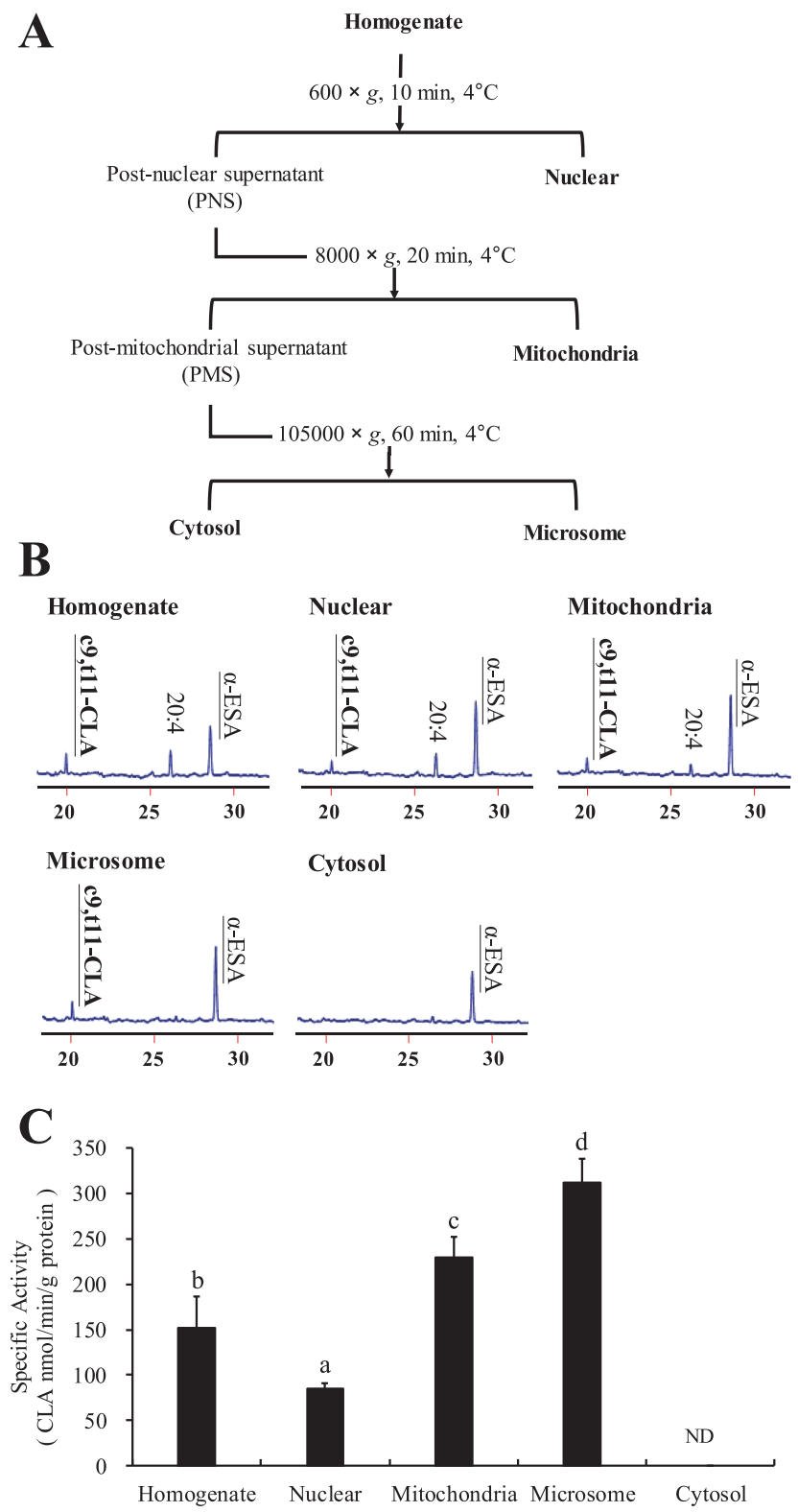

Fig. 1 The specific enzymatic activity of CLA formation in different subcellular fractions separated from mouse liver homogenate. (A) Procedures for ultracentrifugal subcellular fractionation of liver homogenate. Nuclei, mitochondria and microsomes were re-suspended into 1 volume of homogenizing buffer. (B) GCs of free fatty acids from one replicate of a representative experiment in the subcellular fractions. (C) Bar graph analysis of the specific activity of CLA formation in subcellular fractions. ${ }^{a, b, c, d}$ Values without a common letter are significantly different $(p<0.05)$. Data are presented as Mean $\pm \mathrm{SD}, \mathrm{n}=3$. ND, not detected. CLA, conjugated linoleic acid; GCs, gas chromatographs. 
A
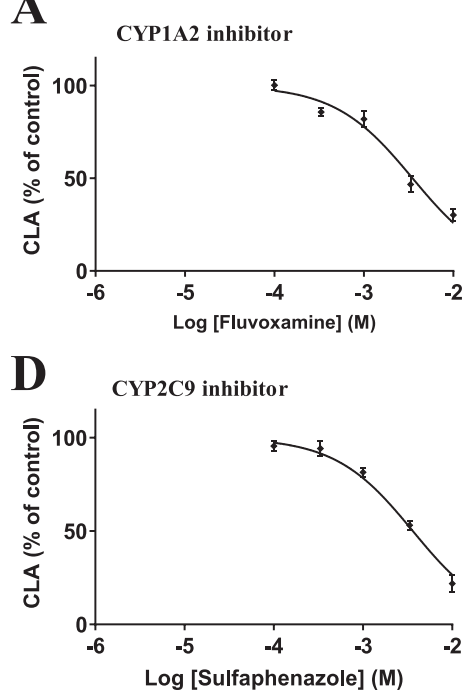

\section{G}

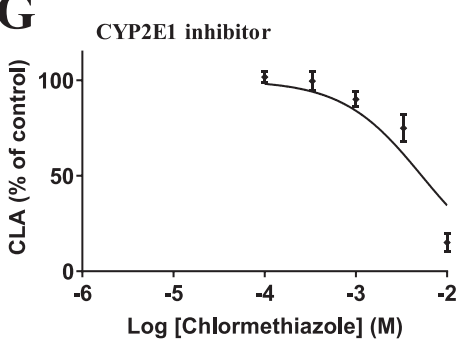

J

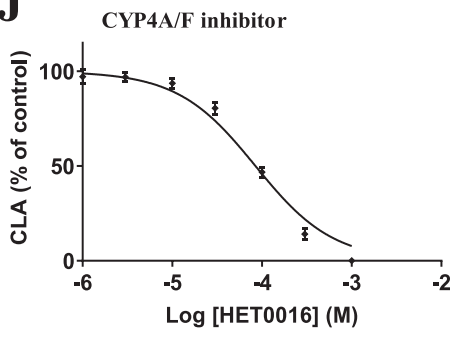

M

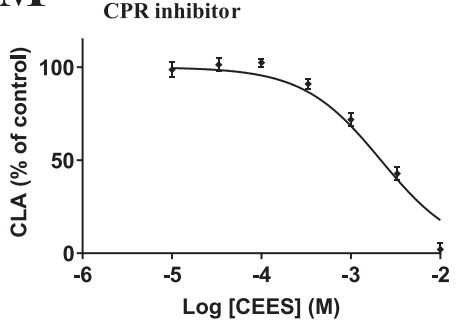

B

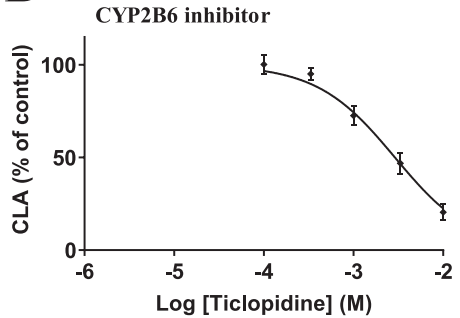

E CYP2C19 inhibitor

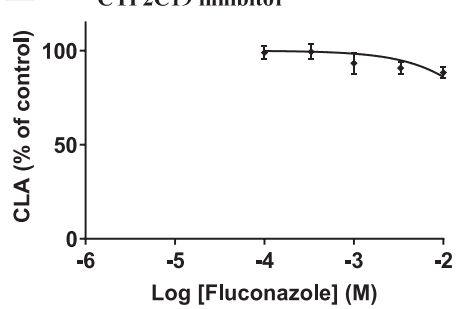

H

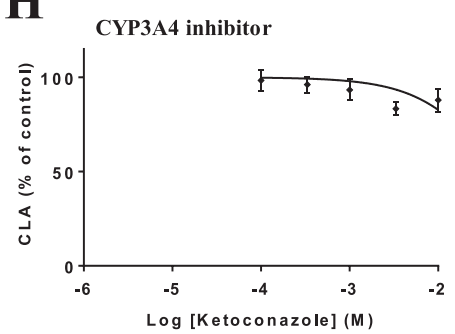

K

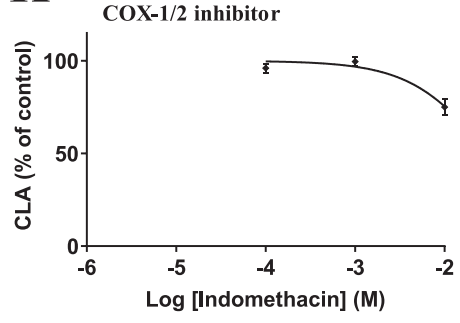

C

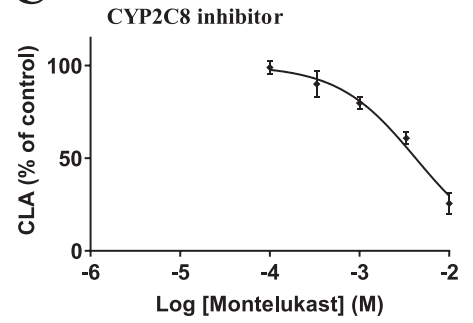

F CYP2D6 inhibitor

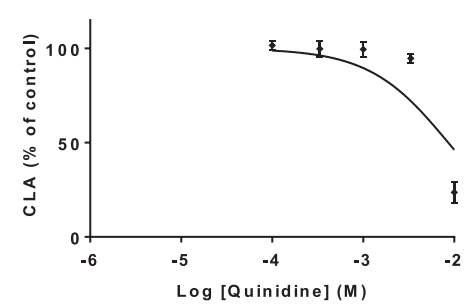

I

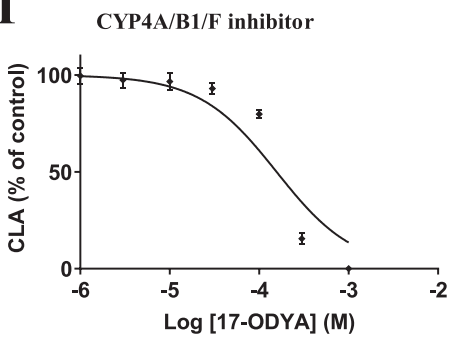

L

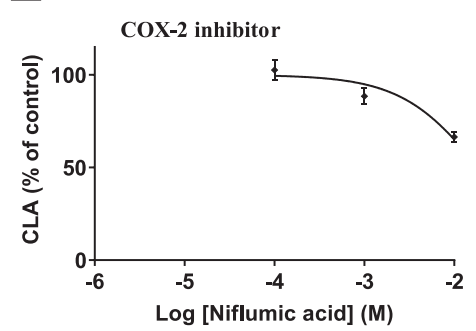

Fig. 2 Inhibitory effect of inhibitors in the conversion of $\alpha$-ESA into CLA in hepatic microsomes. The hepatic microsomes were pre-incubated with inhibitors or DMSO for 5 min as described in the Materials and Methods sections. Cytochrome P450 (CYP) enzymatic activities were inhibited by the corresponding CYP-specific inhibitors (A-J) and the leukotriene $\mathrm{B}_{4}$ 12-hydroxydehydrogenase/15-ketoprostaglandin Delta 13-reductase (LTB4 12-HD/PGR) enzyme was inhibited by the cyclooxygenase (COX)inhibitors indomethacin and niflumic acid (K, L). The NADPHcytochrome P450 reductase (CPR)activity was inhibited by CEES(M). Data are expressed as percentage of the control (no inhibitor), $\mathrm{n}=3 . \mathrm{IC}_{50}$ values are listed in Table 2. CEES, 2-chloroethyl ethyl sulfide; DMSO, dimethyl sulfoxide; $\alpha$-ESA, $\alpha$-eleostearic acid; CLA, conjugated linoleic acid; NADPH, nicotinamide adenine dinucleotide phosphate. 
Table 2 Experimentally determined inhibition rate of inhibitors $(1 \mathrm{mM}$ and $0.1 \mathrm{mM})$ in the conversion of $\alpha$-ESA into CLA and $\mathrm{IC}_{50}$ values.

\begin{tabular}{l|lccc}
\hline \multicolumn{1}{c|}{ Inhibitors } & \multicolumn{1}{c}{ Enzymes } & \multicolumn{1}{c}{$1 \mathrm{mM}$} & $0.1 \mathrm{mM}$ & $\mathrm{IC}_{50}$ \\
\hline \multirow{4}{*}{ Fluvoxamine } & CYP1A2 & $18.1 \pm 4.4^{\mathrm{bc}}$ & $-0.2 \pm 2.9^{\mathrm{c}}$ & $3.5 \pm 0.6^{\mathrm{b}}$ \\
Ticlopidine & CYP2B6 & $27.4 \pm 5.1^{\mathrm{b}}$ & $-0.2 \pm 5.3^{\mathrm{c}}$ & $2.9 \pm 0.5^{\mathrm{bc}}$ \\
Montelukast & CYP2C8 & $20.2 \pm 3.4^{\mathrm{bc}}$ & $1.0 \pm 3.4^{\mathrm{c}}$ & $4.2 \pm 0.7^{\mathrm{b}}$ \\
Sulfaphenazole & CYP2C9 & $18.6 \pm 2.4^{\mathrm{bc}}$ & $4.4^{\mathrm{c}} \pm 2.8^{\mathrm{c}}$ & $3.8 \pm 0.4^{\mathrm{b}}$ \\
Fluconazole & CYP2C19 & $6.7 \pm 5.7^{\mathrm{cd}}$ & $1.0 \pm 3.4^{\mathrm{c}}$ & - \\
Quinidine & CYP2D6 & $-1.6 \pm 2.5^{\mathrm{d}}$ & $0.5 \pm 4.1^{\mathrm{c}}$ & $8.6 \pm 0.6^{\mathrm{a}}$ \\
Chlormethiazole & CYP2E1 & $9.9 \pm 3.9^{\mathrm{c}}$ & $-1.7 \pm 2.7^{\mathrm{c}}$ & $5.3 \pm 1.6^{\mathrm{b}}$ \\
Ketoconazole & CYP3A4 & $6.7 \pm 4.6^{\mathrm{cd}}$ & $1.6 \pm 5.5^{\mathrm{c}}$ & - \\
17-ODYA & CYP4A/B1/F & $100 \pm 0^{\mathrm{a}}$ & $20.2 \pm 2.2^{\mathrm{b}}$ & $0.16 \pm 0.02^{\mathrm{d}}$ \\
HET0016 & CYP4A/F & $100 \pm 0^{\mathrm{a}}$ & $53.2 \pm 2.7^{\mathrm{a}}$ & $0.085 \pm 0.099^{\mathrm{e}}$ \\
Indomethacin & COX-1/2 & $3.9 \pm 2.5^{\mathrm{cd}}$ & $0.8 \pm 1.7^{\mathrm{c}}$ & - \\
Niflumic acid & COX-2 & $11.6 \pm 4.4^{\mathrm{c}}$ & $-1.3 \pm 4.6^{\mathrm{c}}$ & - \\
CEES & $\mathrm{CPR}$ & $28.2 \pm 3.6^{\mathrm{b}}$ & $-1.2 \pm 1.8^{\mathrm{c}}$ & $2.2 \pm 0.3^{\mathrm{c}}$ \\
\hline
\end{tabular}

Data are presented as Mean $\pm \mathrm{SD}, \mathrm{n}=3$. ${ }^{\mathrm{a}, \mathrm{b}, \mathrm{c}, \mathrm{d}}$ Values in a column without a common superscript letter are significantly different $(p<0.05)$.

fluvoxamine (CYP1A2 inhibitor), ticlopidine (CYP2B6 inhibitor), montelukast (CYP2C8 inhibitor), sulfaphenazole (CYP2C9 inhibitor), quinidine (CYP2D6 inhibitor), chlormethiazole (CYP2E1 inhibitor), 17-ODYA (CYP4A/B1/F inhibitor), and HET0016 (CYP4A/B1/F inhibitor), inhibited CLA formation at different concentrations. Furthermore, the activity of leukotriene B4 12-hydroxydehydrogenase/ 15-ketoprostaglandin Delta 13-reductase (LTB 4 12-HD/ PGR), which was thought to be involved in the conversion of $\alpha$-ESA into CLA, could be inhibited by cyclooxygenase (COX) inhibitors, such as indomethacin and niflumic acid. However, the results demonstrated that either indomethacin or niflumic acid had a slight inhibitory effect on CLA formation at a high concentration (Fig. 2, Table 2). Conversely, the inhibitor CEES of cytochrome P450 reductase (CPR) required for electron transfer from NADPH to CYP significantly inhibited CLA formation with an $\mathrm{IC}_{50}$ value of $2.2 \pm 0.3 \mathrm{mM}$ (Table 2). On the other hand, 17-ODYA and HET0016 showed a significantly higher inhibitory level than all the other inhibitors. Specifically, CLA formation was completely inhibited by 17-ODYA and HET0016 at a concentration of $1 \mathrm{mM}$. The inhibition ratio of 17-ODYA was about half that of HET0016 at $0.1 \mathrm{mM}(20.2 \pm 2.2 \%$ versus $53.2 \pm 2.7 \%$ ), and the $\mathrm{IC}_{50}$ value of 17-ODYA was about two-fold that of HET0016 $(0.16 \pm 0.02 \mathrm{mM}$ versus $0.085 \pm 0.099 \mathrm{mM})$, but still significantly lower than that of other CYP1-3 inhibitors. These results thus indicate that the NADPH-dependent CPR/CYP4 electron transport system contribute to the conversion of $\alpha$-ESA into CLA.

\subsection{Difference in enzymatic activities and Cyp4 mRNA expression in various tissues}

By comparing the specific activity of CLA formation and the expression level of Cyp 4 family genes in tissues, we investigated the specific CYP4 enzyme involved in the conversion of $\alpha$-ESA into CLA. The specific enzymatic activity of CLA formation was determined in various tissue homogenates (in a total of 10 tissues), and the activity levels from the most to the least active tissues were as follows: liver, kidney, small intestine, and pancreas, while activity was non-detected in other tissues (Fig. 3A). In addition, the mRNA expression levels of a total of 10 Cyp 4 family genes were examined to determine the tissue distribution patterns of these genes. The results of the relative mRNA expression level analysis illustrated that Cyp 4 family genes exhibited highly different tissue-divergent distribution patterns (Fig. 3B). Furthermore, Cyp $4 a$ subfamily isoforms were almost exclusively found in the liver and kidney. The highest expression of Cyp $4 a 10$ and Cyp $4 a 12 a / b$ were found in the kidney, and the highest Cyp $4 a 14$ mRNA expression was detected in the liver, while Cyp $4 b 1$ was expressed almost entirely in kidney. Cyp $4 f 13$ was expressed ubiquitously in various tissues with the highest expression in the liver followed by kidney, BAT, and small intestine. Cyp $4 f 14$ and $4 f 15$ were primarily expressed in the liver, and fairly low amounts were observed in the small intestine, brain, and kidney. Cyp $4 f 16,4 f 17$, and $4 f 18$ were all expressed ubiquitously like Cyp $4 \mathrm{f} 13$ across tissues. Cyp $4 f 16$ mRNA was high in both the kidney and small intestine, while Cyp $4 f 17$ mRNA was highest in the liver and 
A

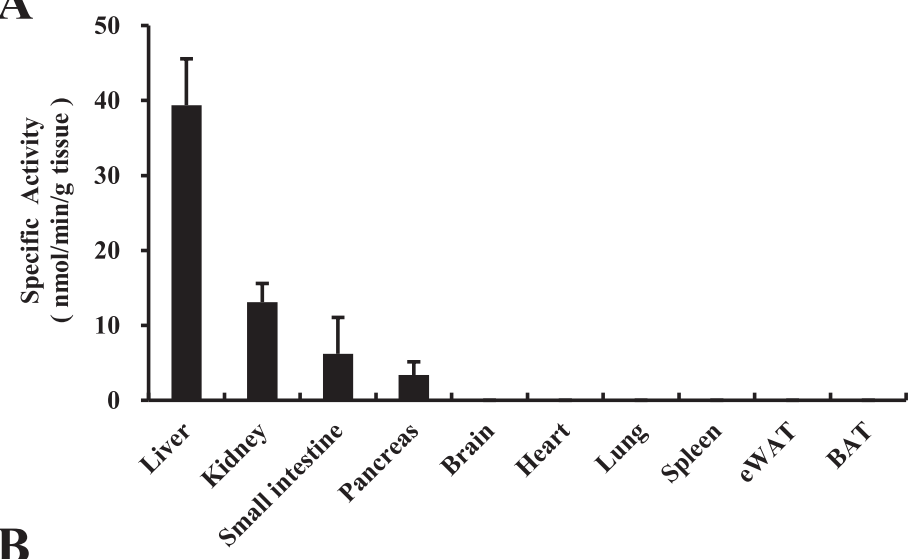

B
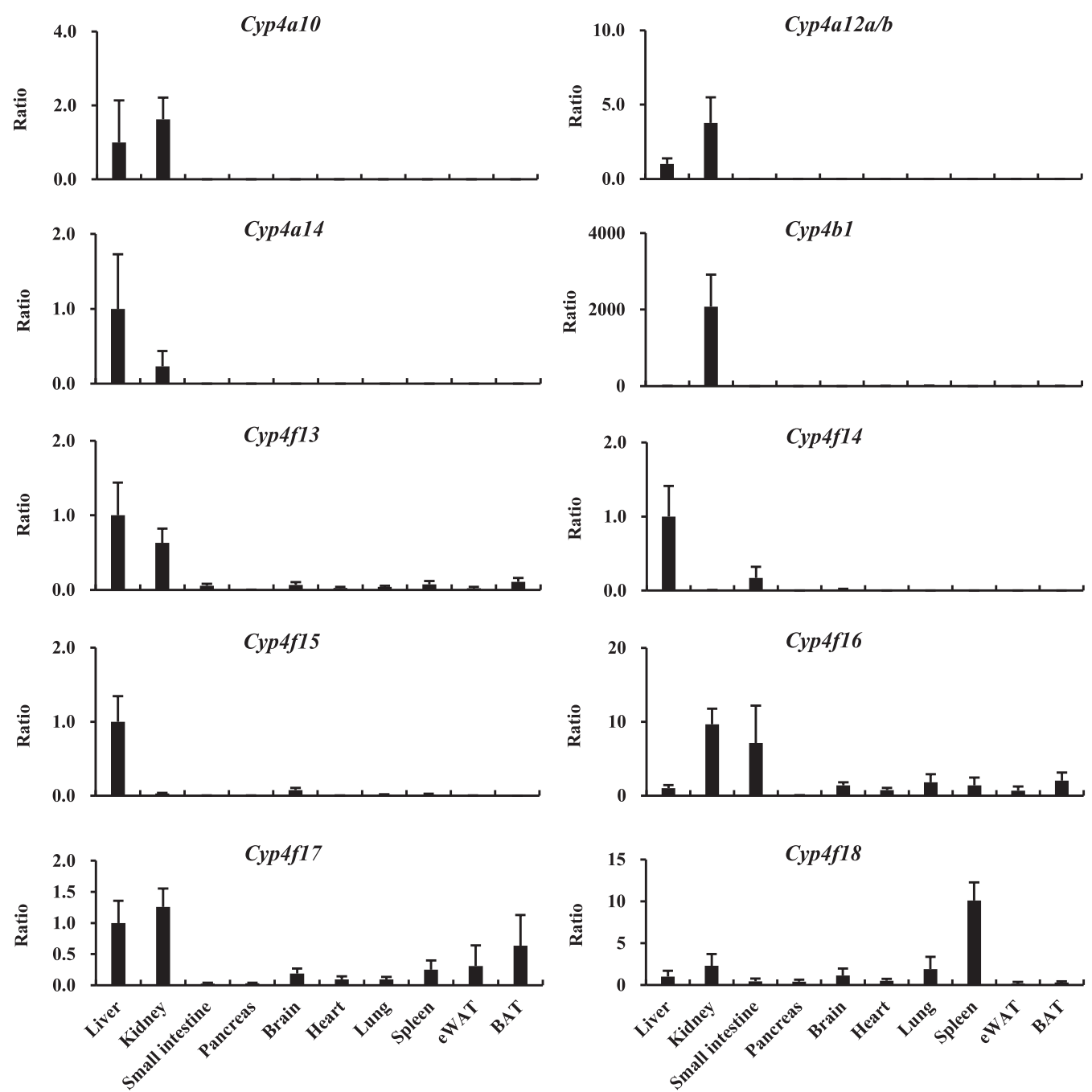

Fig. 3 Comparison of the specific activity of CLA formation and the expression level of Cyp 4 family genes in various tissues. (A) The specific activity of $\alpha$-ESA conversion into CLA in various tissues. The specific activity was normalized to tissue weight: specific activity $(\mathrm{nmol} / \mathrm{min} / \mathrm{g}$ tissue $)=\mathrm{CLA}$ amounts $(\mathrm{nmol}) /$ time taken $(\mathrm{min}) /$ tissue weight $(\mathrm{g})$. (B) The relative expression level of Cyp 4 family genes in each tissue. The gene expression level was normalized to tissue weight and shown as fold changes relative to the corresponding Cyp 4 transcripts in the liver. Fourteen weeks old male mice were used for this experiment. Data are presented as Mean \pm SD, $n=6$. CLA, conjugated linoleic acid; $\alpha$-ESA, $\alpha$-eleostearic acid; eWAT, epididymal white adipose tissue; BAT, brown adipose tissue. 

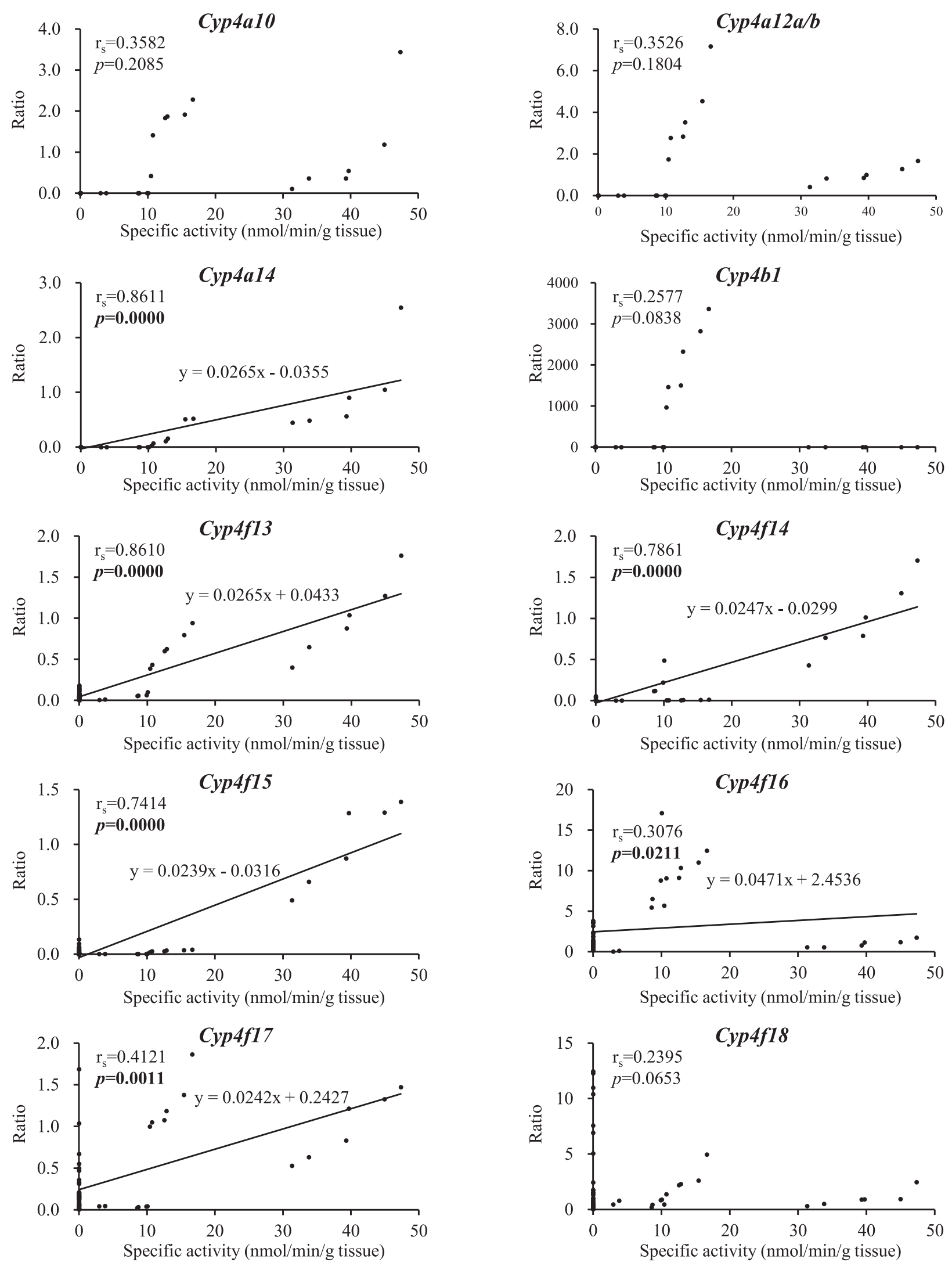

Fig. 4 Spearman's rank correlations between the specific activity of conjugated linoleic acid (CLA) formation and the relative expression level of Cyp 4 family genes in various tissues. Data points $=60$. 
kidney and slightly lower in BAT, eWAT, the spleen, and brain. Cyp $4 f 18$ mRNA was most highly expressed in the spleen. These extensive analysis of Cyp 4 mRNA expression levels provides valuable information about the specific CYP4 enzymes that may be involved in CLA formation in various tissues.

\subsection{Correlation analysis}

The observed disparity between the tissue-divergent expression patterns of Cyp 4 genes and the alterations in the specific activities of CLA formation in tissues pointed to the necessity of a correlation study, which was used to confirm the specific CYP4 enzymes in the conversion of $\alpha$-ESA into CLA. The results are displayed as the specific activity of CLA formation in 10 tissues from 6 male ICR mice versus the relative expression levels of each of the Cyp 4 family genes (Fig. 4). There were no significant correlations between the specific activities and the expression levels of the Cyp $4 a 10,4 a 12 a / b, 4 b 1$, or $4 f 18$ genes. The best correlations were found in Cyp $4 a 14$ and $4 f 13\left(\mathrm{r}_{\mathrm{s}}\right.$ values of 0.8611 and 0.8610 , respectively) with a very high statistical significance $(p<0.0001)$. Cyp $4 f 14$ and $4 \mathrm{f15}$ had very strong positive correlations with a very high statistical significance. A moderate and a strong statistically significant positive correlation were detected in Cyp 4 f16 and Cyp $4 f 17$, respectively. Therefore, the specific activity of CLA formation showed the most similar tissue-distribution pattern with the gene expression patterns of Cyp $4 a 14$ and Cyp 4 f13. These results confirmed that CYP4 enzymes are involved in CLA formation, with CYP4F13 and CYP4A14 being the most relevant enzymes.

\subsection{The effect of CYP-substrates on CLA formation}

To further investigate the role of the most relevant enzymes, CYP4F13 and CYP4A14, in the conversion of $\alpha$-ESA into CLA, the liver microsomes were incubated simultaneously with CYP-substrates, $\alpha$-ESA, and NADPH to test whether the CYP-substrates inhibit CLA formation. The results show that the yield of CLA formation varied in relation to the mole ratios of $\alpha$-ESA and CYP-substrates (Figs. S3 and S4). The CLA formation was significantly inhibited by prostaglandin $\mathrm{A}_{1}\left(\mathrm{PGA}_{1}\right)$ even at a low concentration(Table 3 and Fig. S3), while lauric acid showed no inhibition of CLA formation based on the comparison between CYP-substrate groups (Table 3 ). The other CYPsubstrates were proved to have a significant inhibitory effect only at a high concentration. $\mathrm{PGA}_{1}$, the substrate of CYP4F, appeared to be the most potent substrate, while lauric acid, the substrate of CYP4A and CYP4B1, was the least potent substrate. Taken together, these results suggested that the $\alpha$-ESA saturase that could convert $\alpha$-ESA into CLA belongs to the CYP4F subfamily of enzymes, rather than the CYP4A or CYP4B subfamily of enzymes. Furthermore, the results of the correlation analysis described above confirmed that CYP4F13 is most suitable candidate enzyme among CYP4F subfamily involved in the conversion of $\alpha$-ESA into CLA.

\section{Discussion}

In this study, we demonstrated that the conversion of $\alpha$-ESA into CLA occurs through an NADPH-dependent enzymatic reaction. Furthermore, the highest specific activity of CLA formation was detected in the liver, followed by the kidney, small intestine, and pancreas (Figs. S1-2 and Fig. 3A). These results are consistent with an earlier study conducted with rats by our laboratory ${ }^{18)}$. Moreover, we de-

Table 3 Inhibitory effect of various CYP-substrates in the conversion of $\alpha$-ESA into CLA.

\begin{tabular}{|c|c|c|c|}
\hline \multirow[b]{2}{*}{ Substrates } & \multicolumn{2}{|c|}{$\begin{array}{c}\text { Mole Ratio } \\
(\alpha \text {-ESA : CYP-Substrate) }\end{array}$} & \multirow{2}{*}{ Relevant CYP Enzymes } \\
\hline & $1: 1$ & $1: 4$ & \\
\hline DMSO\# & $100.0 \pm 10.1^{\mathrm{a}}$ & $100.0 \pm 1.3^{\mathrm{a}}$ & \\
\hline Lauric Acid (C12:0) & $98.2 \pm 3.0^{\mathrm{a}}$ & $90.8 \pm 3.4^{\mathrm{ab}}$ & CYP4A, CYP4B1 \\
\hline Palmitic Acid (C16:0) & $91.2 \pm 1.8^{\mathrm{a}}$ & $78.9 \pm 1.0^{\mathrm{bc}}$ & CYP1-3, CYP4F \\
\hline Stearic Acid (C18:0) & $93.4 \pm 7.1^{\mathrm{a}}$ & $78.5 \pm 3.8^{\mathrm{bc}}$ & CYP1-3, CYP4F \\
\hline Oleic Acid (C18:1) & $88.8 \pm 4.3^{\mathrm{a}}$ & $77.3 \pm 8.7^{\mathrm{c}}$ & CYP1-3, CYP4F \\
\hline Linoleic Acid (C18:2) & $92.4 \pm 3.2^{\mathrm{a}}$ & $74.7 \pm 3.0^{\mathrm{c}}$ & CYP1-3, CYP4F \\
\hline Linolenic Acid (C18:3) & $96.8 \pm 3.4^{\mathrm{a}}$ & $76.6 \pm 4.9^{\mathrm{c}}$ & CYP1-3, CYP4F \\
\hline Arachidonic Acid (C20:4) & $98.9 \pm 3.0^{\mathrm{a}}$ & $76.4 \pm 2.1^{\mathrm{c}}$ & CYP4A10, CYP4A12A/B, CYP4F \\
\hline Prostaglandin $\mathrm{A}_{1}\left(\mathrm{C}_{20} \mathrm{H}_{32} \mathrm{O}_{4}\right)$ & $87.8 \pm 7.3^{b}$ & $73.6 \pm 4.8^{\mathrm{c}}$ & CYP4F \\
\hline
\end{tabular}

Notes: \#, all the substrates were dissolved in DMSO which is also taken as a control. ${ }^{\mathrm{a}, \mathrm{b}, \mathrm{c}}$ Values in a column without a common superscript letter are significantly different $(p<0.05)$. Data are presented as Mean $\pm \mathrm{SD}, \mathrm{n}=3$. 
termined the subcellular distribution of $\alpha$-ESA saturase in the liver. Our results demonstrate that $\alpha$-ESA saturase was abundant in microsomes, but absent in the cytosol. Liver microsomes contain the major drug-metabolizing enzymes CYP and UDP-glucuronosyltransferase (UGT), along with other enzymes that contribute to drug metabolism ${ }^{37)}$, which support our hypothesis that $\alpha$-ESA saturase should be classified as an enzyme for drug metabolism. To test this hypothesis, CYP-specific inhibitors were selected to validate the effect of inhibitors on CLA formation in hepatic microsomes. The results showed that the inhibitors of CYP $1^{38)}, 2^{39,40)}$, and $3^{41)}$ family enzymes had minimal or modest inhibitory activities. However, CYP1-3 contain major xenobiotic-metabolizing enzymes responsible for the metabolism of the majority of drugs and other xenobiotics ${ }^{42,43)}$, while CYP4 enzymes typically metabolize fatty acids ${ }^{29,44)}$. According to this observation, CYP1-3 are unlikely to play a role in the metabolism of $\alpha$-ESA, which is a type of conjugated triene fatty acid, and the slight inhibitory effect of CYP1-3 inhibitors could be due to a low specificity ${ }^{43,45)}$. In contrast, CYP4 inhibitors, 17-ODYA and HET0016 ${ }^{44,46)}$, showed the highest level of inhibition(Fig. 2), which also indicated that CYP4 enzymes are involved in CLA formation. In addition, the CPR inhibitor of $\mathrm{CEES}^{47)}$ also showed a significant inhibition of CLA formation. All these findings suggested that the CPR/CYP4 electron transport system is involved in the conversion of $\alpha$-ESA into CLA.

We also noticed that the conversion of $\alpha$-ESA into CLA is similar to that in the metabolic pathway of eicosanoids, where leukotriene $\mathrm{B} 4\left(\mathrm{LTB}_{4}\right)$, prostaglandin $\mathrm{E}_{2}\left(\mathrm{PGE}_{2}\right)$, and lipoxinA $\mathrm{A}_{4}\left(\mathrm{LXA}_{4}\right)$ are the dominant eicosanoids. In the LTB4 metabolic pathway, $\mathrm{LTB}_{4}$ is oxidized by $\mathrm{LTB}_{4} 12-\mathrm{HD} / \mathrm{PGR}$ to 12-oxo-LTB 4 , and then the double bonds at C10-C11 and C14-15 are reduced to 10,11,14,15-tetrahydro-12-oxo-LTB 4 by an unknown reductase (s). Additionally, $\mathrm{PGE}_{2}$ and $\mathrm{LXA}_{4}$ are oxidized to 15-oxo-prostaglandin $\mathrm{E}_{2}\left(15\right.$-oxo-PGE $\left.\mathrm{P}_{2}\right)$ and 15-oxo-lipoxinA $\mathrm{A}_{4}$ (15-oxo-LXA 4 ), respectively; $\mathrm{LTB}_{4}$ 12-HD/ PGR subsequently reduces 15 -oxo- $\mathrm{PGE}_{2}$ to 13,14 -dihydro15-oxo-PGE ${ }_{2}$ and 15-oxo-LXA 4 to 13,14-dihydro-15-oxo$\mathrm{LXA}_{4}$ in the presence of $\mathrm{NADPH}^{48)}$. In addition, Clish et $a l .{ }^{49,50)}$ have reported that $\mathrm{LTB}_{4} 12-\mathrm{HD} / \mathrm{PGR}$ is a member of the zinc-independent medium chain dehydrogenase/reductase family, which exhibits high reductase activity toward double bonds in several xenobiotics. Therefore, we speculated that the conversion of $\alpha$-ESA into CLA proceeds through the $\mathrm{LTB}_{4}$ metabolic pathway, in which the double bond of $\alpha$-ESA is saturated by the unknown reductase (s), or the $\mathrm{PGE}_{2}$ and $\mathrm{LXA}_{4}$ pathways, in which the double bond is directly reduced by $\mathrm{LTB}_{4} 12-\mathrm{HD} / \mathrm{PGR}$. However, our study showed that the $\mathrm{LTB}_{4}$ 12-HD/PGR inhibitors, indomethacin and niflumic acid ${ }^{49)}$, caused only a slight inhibitory effect on CLA formation, thereby indicating that $\mathrm{LTB}_{4}$ 12-HD/PGR does not contribute to CLA formation. Moreover, Itoh et al. ${ }^{51}$ have reported that $\mathrm{LTB}_{4}$ 12-HD/PGR from male Wistar rat liver was predominantly localized in the cytosolic fraction, and was absent in the microsomal fraction. In contrast, the $\alpha$-ESA saturase activity was highest in the microsomal fraction and absent in the cytosolic fraction in this study (Fig. 1). This discrepancy also suggests that $\mathrm{LTB}_{4} 12-\mathrm{HD} / \mathrm{PGR}$ is unlikely to play a role in the conversion of $\alpha$-ESA into CLA.

In our previous studies, we have shown that $\alpha$-ESA and PA were converted into c9,t11-CLA, JA was converted into c8,t10-CLA in rats, and the conversion ratio of $\alpha$-ESA was higher than that of PA and JA. These results indicate that the double bond distal to the carboxyl group in the carbon chain of the conjugated triene acid is selectively saturated in this reaction and the variety in the conversion ratios may be attributed to the substrate-specificity of the saturase. Furthermore, these findings suggested that CYP-substrates could be utilized to determine which specific CYP4 enzyme catalyzed $\alpha$-ESA metabolism. Lauric acid, a specific substrate of CYP4A enzymes ${ }^{44)}$, also preferentially catalyzed by the rabbit CYP4B1 enzyme ${ }^{52)}$ but not the CYP4F enzymes, had no inhibitory effect on CLA formation. Moreover, there were no statistically significant differences in the inhibitory effects between palmitic acid (C16:0), C18 carbon fatty acids (non-conjugated fatty acids with the same number of carbon atoms as $\alpha$-ESA but with a variety in the number of double bond), and arachidonic acid (C20:4). This finding suggests that the number of carbon atoms and the non-conjugated double bond have no effect on the substrate-specific effects of $\alpha$-ESA saturase. In addition, we found no inhibitory effect from the other CYP4F substrates at low concentrations except for $\mathrm{PGA}_{1}$, which is one of the "classical" substrates of CYP4F enzymes, since other CYP4F-substrates could also be catalyzed by other CYP family enzymes besides CYP4F.

Taken together, these findings led us to select CYP4F isoforms as $\alpha$-ESA saturase, consistent with previous reports showing that CYP4As metabolize intermediatechain fatty acids (fatty acids with C10 to 16 carbon chain) ${ }^{29)}$, while CYP4Fs catalyze long-chain fatty acids (C16 to 26) ${ }^{53)}$. However, we could not determine the specific CYP4F enzyme involved due to a lack of a selective marker substrate for the activity of individual CYP4F enzymes in the study of the effect of CYP-substrates on CLA formation, although $\mathrm{PGA}_{1}$ could be used as a nonselective marker substrate for CYP4F enzymes. Nonetheless, the correlation analysis showed that Cyp $4 a 14$ and $4 f 13$ had the best correlation with a very high statistical significance. After a comprehensive evaluation of these findings, we concluded that CYP4F13 was the primary enzyme involved in CLA formation. Conversely, CYP4B1 was predominantly expressed in extrahepatic tissues and has been reported to preferentially metabolize short-chain fatty acids (approximately $\mathrm{C} 7$ to $10{ }^{52)}$, suggesting that CYP4B1 does not contribute to CLA formation. This is also verified by the results 
of the correlation study.

CYP enzymes almost always act as monooxygenases, or mixed-function oxidases by inserting one atomic oxygen into the substrate. The stoichiometry of the oxidation reaction can be written as: $\mathrm{R}-\mathrm{H}+\mathrm{NADPH}+\mathrm{O}_{2} \rightarrow \mathrm{ROH}+\mathrm{H}_{2} \mathrm{O}+$ $\mathrm{NADP}^{+}{ }^{54)}$. The CYP4 family plays a major role in the metabolism of fatty acids, in most cases through oxidation of fatty acids, including epoxidation and hydroxylation. Unlike the well-established oxidation reaction, the reduction reaction catalyzed by CYP has not been characterized in detail. The stoichiometry is written as: $\mathrm{R}=\mathrm{X}+\mathrm{NADPH}$ $+\mathrm{H}^{+} \rightarrow \mathrm{RH}-\mathrm{XH}+\mathrm{NADP}^{\left.+{ }^{55}\right)}$. This reaction is mostly seen when the substrates contain quinones, azo-, halogenated, nitro-, N-hydroxy-, and hydroperoxide functional groups. Amunom et $a l .{ }^{55,56)}$ have reported that $\alpha, \beta$-unsaturated aldehydes (9-anthracene aldehyde and 4-hydroxy-trans2-nonenal) are reduced/hydrogenated to their corresponding carboxylic acid by several human and murine CYP enzymes. They also identified that this CYP-dependent reduction occurred in the presence and absence of molecular oxygen. Furthermore, replacement of the normal ambient air with carbon monoxide did not affect the reaction but significantly inhibited CYP-dependent oxidation. We also found that there was no significant difference in the specific activity of CLA formation in tissues determined under ambient air conditions and under nitrogen flow (weak anaerobic) conditions (data not shown). The CLA formation reaction would be more similar to CYP-dependent reduction rather than CYP-dependent oxidation in terms of molecular oxygen requirement. Although, to our knowledge, there have been no previously documented reports that unsaturated fatty acids can be reduced/hydrogenated by CYP, the precedent aldehyde group reduction suggests that there may be other functional groups, such as conjugated double bonds in fatty acids, which also can be reduced by CYP.

Mice have 102 CYP enzymes and many of the recently identified CYP enzymes are still considered "orphans" with no known functions ${ }^{57)}$. In particular, the physiological and metabolic functions of the CYP4F subfamily have not been elucidated, only the catalytic activities of CYP4F14 and 4F18 are known, while other enzymes remain to be characterized $^{58)}$. From our results we inferred that CYP4F13 is the major enzyme responsible for the conversion of $\alpha$-ESA into CLA, indicating that there may be a novel reduction reaction pathway for fatty acid metabolism in the liver, besides epoxidation and hydroxylation by CYP. This reduction reaction may be a unique function of CYP4Fs which remains to be fully understood. Thus, it will be of great interest to further examine the possible metabolic and functional effects of CYP4F in vivo at the molecular and physiological levels to extend our knowledge of CYP4F functions. As part of future research efforts, we intend to isolate and purify the CYP4F13 enzyme from mouse liver to provide direct evidence of the $\alpha$-ESA to CLA conversion reaction.

\section{Conclusion}

In summary, to our knowledge, the present study would be the first to characterize CYP4F13 as the major enzyme responsible for the conversion of $\alpha$-ESA into CLA. Whether it plays a role in the conversion of other CLnA, such as PA and JA, into CLA remains to be explored.

\section{Acknowledegment}

We thank Dr. Keiichi Konoki for his kind assistance. The authors declare that there are no conflicts of interest. This research was supported by grants from the Project of the NARO Bio-oriented Technology Research Advancement Institution (Advanced integration research for agriculture and interdisciplinary fields).

\section{Supporting Information}

This material is available free of charge via the Internet at http://dx.doi.org/jos.69.10.5650/jos.ess20080

\section{Reference}

1) Benjamin, S.; Prakasan, P.; Sreedharan, S.; Wright, A.D.; Spener, F. Pros and cons of CLA consumption: an insight from clinical evidences. Nutr. Metab. 12, 777-780 (2015).

2) de Carvalho, E.B.T.; de Melo, I.L.P.; Mancini-Filho, J. Chemical and physiological aspects of isomers of conjugated fatty acids. J. Food Sci. Technol. 30, 295-307 (2010).

3) Eynard, A.R.; Lopez, C.B. Conjugated linoleic acid (CLA) versus saturated fats/cholesterol: Their proportion in fatty and lean meats may affect the risk of developing colon cancer. Lipids Health Dis. 2, 6 (2003).

4) Kumari, S.; Yong Meng, G.; Ebrahimi, M. Conjugated linoleic acid as functional food in poultry products: A review. Int. J. Food Prop. 20, 491-506(2016).

5) Khanal, R.C.; Dhiman, T.R. Biosynthesis of conjugated linoleic acid (CLA): A review. Pakistan. J. Nutr. 3, 72-81 (2004).

6) Miranda, J.; Arias, N.; Fernandez-Quintela, A.; del Puy Portillo, M. Are conjugated linolenic acid isomers an alternative to conjugated linoleic acid isomers in obesity prevention? Endocrinol. Nutr. 61, 209-219 (2014). 
7) Pariza, M.W.; Park, Y.; Cook, M.E. Mechanisms of action of conjugated linoleic acid: Evidence and speculation. Proc. Soc. Exp. Biol. Med. 223, 8-13(2000).

8) Clement, L.; Poirier, H.; Niot, I.; Bocher, V.; GuerreMillo, M.; Krief, S.; Staels, B.; Besnard, P. Dietary trans-10,cis-12 conjugated linoleic acid induces hyperinsulinemia and fatty liver in the mouse. J. Lipid Res. 43, 1400-1409(2002).

9) Park, Y.; Pariza, M.W. Mechanisms of body fat modulation by conjugated linoleic acid (CLA). Food Res. Int. 40, 311-323 (2007).

10) Poirier, H.; Shapiro, J.S.; Kim, R.J.; Lazar, M.A. Nutritional supplementation with trans-10, cis-12-conjugated linoleic acid induces inflammation of white adipose tissue. Diabetes 55, 1634-1641 (2006).

11) Riserus, U.; Arner, P.; Brismar, K.; Vessby, B. Treatment with dietary trans 10 cis 12 conjugated linoleic acid causes isomer-specific insulin resistance in obese men with the metabolic syndrome. Diabetes Care 25, 1516-1521 (2002).

12) Song, H.J.; Sneddon, A.A.; Barker, P.A.; Bestwick, C.; Choe, S.N.; McClinton, S.; Grant, I.; Rotondo, D.; Heys, S.D.; Wahle, K.W. Conjugated linoleic acid inhibits proliferation and modulates protein kinase $\mathrm{C}$ isoforms in human prostate cancer cells. Nutr. Cancer 49, 100108(2004).

13) Tsuzuki, T.; Kawakami, Y.; Abe, R.; Nakagawa, K.; Koba, K.; Imamura, J.; Iwata, T.; Ikeda, I.; Miyazawa, T. Conjugated linolenic acid is slowly absorbed in rat intestine, but quickly converted to conjugated linoleic acid. J. Nutr. 136, 2153-2159(2006).

14) Tsuduki, T. Research on food and nutrition characteristics of conjugated fatty acids. Biosci. Biotechnol. Biochem. 79, 1217-1222(2015).

15) Tsuzuki, T.; Kawakami, Y. Tumor angiogenesis suppression by alpha-eleostearic acid, a linolenic acid isomer with a conjugated triene system, via peroxisome proliferator-activated receptor gamma. Carcinogenesis 29, 797-806 (2008).

16) Shinohara, N.; Tsuduki, T.; Ito, J.; Honma, T.; Kijima, R.; Sugawara, S.; Arai, T.; Yamasaki, M.; Ikezaki, A.; Yokoyama, M.; Nishiyama, K.; Nakagawa, K.; Miyazawa, T.; Ikeda, I. Jacaric acid, a linolenic acid isomer with a conjugated triene system, has a strong antitumor effect in vitro and in vivo. Biochim. Biophys. Acta 1821, 980-988(2012).

17) Tsuzuki, T.; Tokuyama, Y.; Igarashi, M.; Miyazawa, T. Tumor growth suppression by alpha-eleostearic acid, a linolenic acid isomer with a conjugated triene system, via lipid peroxidation. Carcinogenesis 25, 1417-1425 (2004).

18) Tsuzuki, T.; Tokuyama, Y.; Igarashi, M.; Nakagawa, K.; Ohsaki, Y.; Komai, M.; Miyazawa, T. alpha-eleostearic $\operatorname{acid}(9 \mathrm{Z11E} 13 \mathrm{E}-18: 3)$ is quickly converted to conjugat- ed linoleic acid(9Z11E-18:2) in rats. J. Nutr. 134, 2634-2639 (2004).

19) Tsuzuki, T.; Igarashi, M.; Komai, M.; Miyazawa, T. The metabolic conversion of 9,11,13-eleostearic acid (18 : $3)$ to 9,11 -conjugated linoleic acid $(18: 2)$ in the rat. $J$. Nutr. Sci. Vitaminol. 49, 195-200(2003).

20) Kijima, R.; Honma, T.; Ito, J.; Yamasaki, M.; Ikezaki, A.; Motonaga, C.; Nishiyama, K.; Tsuduki, T. Jacaric acid is rapidly metabolized to conjugated linoleic acid in rats. J. Oleo Sci. 62, 305-312(2013).

21) Yuan, G.-F.; Sinclair, A.J.; Zhou, C.-Q.; Li, D. $\alpha$-Eleostearic acid is more effectively metabolized into conjugated linoleic acid than punicic acid in mice. $J$. Sci. Food Agric. 89, 1006-1011 (2009).

22) Yuan, G.; Sinclair, A.J.; Xu, C.; Li, D. Incorporation and metabolism of punicic acid in healthy young humans. Mol. Nutr. Food Res. 53, 1336-1342(2009).

23) Schneider, A.C.; Mignolet, E.; Schneider, Y.J.; Larondelle, Y. Uptake of conjugated linolenic acids and conversion to cis-9, trans-11-or trans-9, trans-11-conjugated linoleic acids in Caco-2 cells. Br. J. Nutr. 109, 57-64(2013).

24) Lourenco, M.; Ramos-Morales, E.; Wallace, R.J. The role of microbes in rumen lipolysis and biohydrogenation and their manipulation. Animal 4, 1008-1023 (2010).

25) Griinari, J.M.; Corl, B.A.; Lacy, S.H.; Chouinard, P.Y.; Nurmela, K.V.V.; Bauman, D.E. Conjugated linoleic acid is synthesized endogenously in lactating dairy cows by Delta (9)-desaturase. J. Nutr. 130, 2285-2291 (2000).

26) Turpeinen, A.M.; Mutanen, M.; Aro, A.; Salminen, I.; Basu, S.; Palmquist, D.L.; Griinari, J.M. Bioconversion of vaccenic acid to conjugated linoleic acid in humans. Am. J. Clin. Nutr. 76, 504-510 (2002).

27) Corl, B.A.; Barbano, D.M.; Bauman, D.E.; Ip, C. cis-9, trans-11 CLA derived endogenously from trans-11 18 : 1 reduces cancer risk in rats. J. Nutr. 133, 2893-2900 (2003).

28) Santora, J.E.; Palmquist, D.L.; Roehrig, K.L. Transvaccenic acid is desaturated to conjugated linoleic acid in mice. J. Nutr. 130, 208-215 (2000).

29) Jarrar, Y.B.; Lee, S.J. Molecular functionality of cytochrome P450 4(CYP4) genetic polymorphisms and their clinical implications. Int. J. Mol. Sci. 20, 42744291 (2019).

30) Miyamoto, M.; Yamashita, T.; Yasuhara, Y.; Hayasaki, A.; Hosokawa, Y.; Tsujino, H.; Uno, T. Membrane anchor of cytochrome $\mathrm{P} 450$ reductase suppresses the uncoupling of cytochrome P450. Chem. Pharm. Bull. 63, 286-294 (2015).

31) Iwagaki, Y.; Sugawara, S.; Huruya, Y.; Sato, M.; Wu, Q.M.; E, S.; Yamamoto, K.; Tsuduki, T. The 1975 Japanese diet has a stress reduction effect in mice: Search 
for physiological effects using metabolome analysis. Biosci. Biotechnol. Biochem. 82, 709-715(2018).

32) Igarashi, M.; Tsuzuki, T.; Kambe, T.; Miyazawa, T. Recommended methods of fatty acid methylester preparation for conjugated dienes and trienes in food and biological samples. J. Nutr. Sci. Vitaminol. 50, 121-128 (2004).

33) Heinemann, F.S.; Ozols, J. Isolation and structural analysis of microsomal membrane proteins. Front. Biosci. 3, d483-493 (1998).

34) Sakanoi, Y.; E, S.; Yamamoto, K.; Ota, T.; Seki, K.; Imai, M.; Ota, R.; Asayama, Y.; Nakashima, A.; Suzuki, K.; Tsuduki, T. Simultaneous intake of Euglena gracilis and vegetables synergistically exerts an anti-inflammatory effect and attenuates visceral fat accumulation by affecting gut microbiota in mice. Nutrients 10 , (2018).

35) Wu, Q.; E, S.; Yamamoto, K.; Tsuduki, T. Carbohydraterestricted diet promotes skin senescence in senescence-accelerated prone mice. Biogerontology 20, 71-82 (2019).

36) Akoglu, H. User's guide to correlation coefficients. Turk. J. Emerg. Med. 18, 91-93(2018).

37) Knights, K.M.; Stresser, D.M.; Miners, J.O.; Crespi, C.L. In vitro drug metabolism using liver microsomes. Curr. Protoc. Pharmacol. 74, 7.8.1-7.8.24(2016).

38) Turpeinen, M.; Korhonen, L.E.; Tolonen, A.; Uusitalo, J.; Juvonen, R.; Raunio, H.; Pelkonen, O. Cytochrome P450 (CYP) inhibition screening: comparison of three tests. Eur. J. Pharm. Sci. 29, 130-138(2006).

39) Parkinson, A.; Kazmi, F.; Buckley, D.B.; Yerino, P.; Paris, B.L.; Holsapple, J.; Toren, P.; Otradovec, S.M.; Ogilvie, B.W. An evaluation of the dilution method for identifying metabolism-dependent inhibitors of cytochrome P450 enzymes. Drug Metab. Dispos. 39, 1370-1387 (2011).

40) Cederbaum, A.I. Molecular mechanisms of the microsomal mixed function oxidases and biological and pathological implications. Redox Biol. 4, 60-73 (2015).

41) Chen, Z.H.; Zhang, S.X.; Long, N.; Lin, L.S.; Chen, T.; Zhang, F.P.; Lv, X.Q.; Ye, P.Z.; Li, N.; Zhang, K.Z. An improved substrate cocktail for assessing direct inhibition and time-dependent inhibition of multiple cytochrome P450s. Acta Pharmacol. Sin. 37, 708-718 (2016).

42) Guengerich, F.P. Cytochrome p450 and chemical toxicology. Chem. Res. Toxicol. 21, 70-83(2008).

43) Zanger, U.M.; Schwab, M. Cytochrome P450 enzymes in drug metabolism: regulation of gene expression, enzyme activities, and impact of genetic variation. Pharmacol. Ther. 138, 103-141 (2013).

44) Edson, K.Z.; Rettie, A.E. CYP4 enzymes as potential drug targets: Focus on enzyme multiplicity, inducers and inhibitors, and therapeutic modulation of 20-hy- droxyeicosatetraenoic acid(20-HETE) synthase and fatty acid omega-hydroxylase activities. Curr. Top. Med. Chem. 13, 1429-1440(2013).

45) Pelkonen, O.; Myllynen, P.; Taavitsainen, P.; Boobis, A.R.; Watts, P.; Lake, B.G.; Price, R.J.; Renwick, A.B.; Gomez Lechon, M.J.; Castell, J.V.; Ingelman Sundberg, M.; Hidestrand, M.; Guillouzo, A.; Corcos, L.; Goldfarb, P.S.; Lewis, D.F. Carbamazepine: a 'blind' assessment of CVP-associated metabolism and interactions in human liver-derived in vitro systems. Xenobiotica 31, 321-343 (2001).

46) Wang, M.Z.; Saulter, J.Y.; Usuki, E.; Cheung, Y.L.; Hall, M.; Bridges, A.S.; Loewen, G.; Parkinson, O.T.; Stephens, C.E.; Allen, J.L.; Zeldin, D.C.; Boykin, D.W.; Tidwell, R.R.; Parkinson, A.; Paine, M.F.; Hall, J.E. CY$\mathrm{P} 4 \mathrm{~F}$ enzymes are the major enzymes in human liver microsomes that catalyze the O-demethylation of the antiparasitic prodrug DB289[2,5-bis (4-amidinophenyl) furan-bis-O-methylamidoxime]. Drug Metab. Dispos. 34, 1985-1994 (2006).

47) Gray, J.P.; Mishin, V.; Heck, D.E.; Laskin, D.L.; Laskin, J.D. Inhibition of NADPH cytochrome P450 reductase by the model sulfur mustard vesicant 2-chloroethyl ethyl sulfide is associated with increased production of reactive oxygen species. Toxicol. Appl. Pharmacol. 247, 76-82(2010).

48) Hori, T.; Yokomizo, T.; Ago, H.; Sugahara, M.; Ueno, G.; Yamamoto, M.; Kumasaka, T.; Shimizu, T.; Miyano, M. Structural basis of leukotriene B4 12-hydroxydehydrogenase/15-Oxo-prostaglandin 13-reductase catalytic mechanism and a possible Src homology 3 domain binding loop. J. Biol. Chem. 279, 22615-22623 (2004).

49) Clish, C.B.; Sun, Y.P.; Serhan, C.N. Identification of dual cyclooxygenase-eicosanoid oxidoreductase inhibitors: NSAIDs that inhibit PG-LX reductase/LTB (4) dehydrogenase. Biochem. Biophys. Res. Commun. 288, 868-874 (2001).

50) Clish, C.B.; Levy, B.D.; Chiang, N.; Tai, H.H.; Serhan, C.N. Oxidoreductases in lipoxin A4 metabolic inactivation: a novel role for 15-onoprostaglandin 13-reductase/leukotriene B4 12-hydroxydehydrogenase in inflammation. J. Biol. Chem. 275, 25372-25380 (2000).

51) Itoh, K.; Yamamoto, K.; Adachi, M.; Kosaka, T.; Tanaka, Y. Leukotriene B4 12-hydroxydehydrogenase/15-ketoprostaglandin Delta 13-reductase (LTB4 12-HD/PGR) responsible for the reduction of a double-bond of the alpha,beta-unsaturated ketone of an aryl propionic acid non-steroidal anti-inflammatory agent CS-670. Xenobiotica 38, 249-263(2008).

52) Baer, B.R.; Rettie, A.E. CYP4B1: an enigmatic P450 at the interface between xenobiotic and endobiotic metabolism. Drug Metab. Rev. 38, 451-476 (2006).

53) Sanders, R.J.; Ofman, R.; Duran, M.; Kemp, S.; Wan- 
ders, R.J. Omega-oxidation of very long-chain fatty acids in human liver microsomes. Implications for Xlinked adrenoleukodystrophy. J. Biol. Chem. 281, 13180-13187 (2006).

54) Urlacher, V.B.; Girhard, M. Cytochrome P450 monooxygenases in biotechnology and synthetic biology. Trends Biotechnol. 37, 882-897(2019).

55) Amunom, I.; Srivastava, S.; Prough, R.A. Aldehyde reduction by cytochrome P450. Curr. Protoc. Toxicol. Chapter 4: Unit 4.37 (2011).

56) Amunom, I.; Dieter, L.J.; Tamasi, V.; Cai, J.; Conklin, D.J.; Srivastava, S.; Martin, M.V.; Guengerich, F.P.;
Prough, R.A. Cytochromes P450 catalyze the reduction of alpha,beta-unsaturated aldehydes. Chem. Res. Toxicol. 24, 1223-1230(2011).

57) Fu, Z.D.; Selwyn, F.P.; Cui, J.Y.; Klaassen, C.D. RNA sequencing quantification of xenobiotic-processing genes in various sections of the intestine in comparison to the liver of male mice. Drug Metab. Dispos. 44, 842-856 (2016).

58) Kalsotra, A.; Strobel, H.W. Cytochrome P450 4F subfamily: At the crossroads of eicosanoid and drug metabolism. Pharmacol. Ther. 112, 589-611 (2006). 